\title{
Element partitioning and electron backscatter diffraction analysis from feeding wire to as-deposited microstructure of Wire and Arc Additive Manufacturing with super duplex stainless steel
}

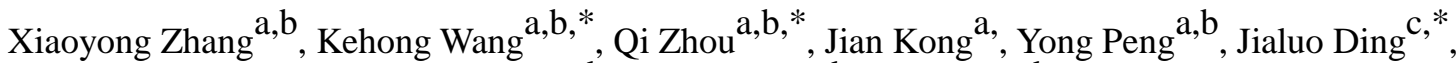 \\ Chenglei Diao ${ }^{\mathrm{c}}$, Dongqing Yang ${ }^{\mathrm{a}, \mathrm{b}}$, Yong Huang ${ }^{\mathrm{a}, \mathrm{b}}$, Tao Zhang ${ }^{\mathrm{d}}$, Stewart. W. Williams ${ }^{\mathrm{c}}$
}

\footnotetext{
a School of Materials Science and Engineering, Nanjing University of Science and Technology, Nanjing, 210094, China

${ }^{b}$ Key Laboratory of Controlled Arc Intelligent Additive Manufacturing Technology, Ministry of Industry and Information Technology, Nanjing University of Science and Technology, Nanjing, 210094, China

${ }^{c}$ Welding Engineering and Laser Processing Center, Cranfield University, Cranfield, MK43 0AL, UK

$\mathrm{d}$ College of Mechanic and Electrical Engineering, Nanjing University of Aeronautics and Astronautics, Nanjing 210016, China;

*1 Corresponding author, e-mail: khWang1602@126.com, Tel.: +86 $\underline{\text { 025-84315776 }}$

$*_{2}$ Corresponding author, e-mail: cheezhou @ njust.edu.cn, Tel.: +86 025-84315776

*3 Corresponding author, e-mail: jialuo.ding@ cranfield.ac.uk, Tel.: 0044750111-5052
}

\begin{abstract}
The redistribution of alloying elements and the crystallographic characterizations in wire and arc additive manufactured (WAAM) super duplex stainless steel (SDSS) was investigated from the wire to the final as-deposited structure. The results showed that elemental partitioning between austenite and ferrite was suppressed in the last layer and the solidified droplet. The high Ni content but low $\mathrm{Cr}$ and $\mathrm{N}$ contents in the initial state of the intragranular austenite (IGA) confirmed the predominance of the chromium nitrides acted as the nucleation sites. Gathering of nitrogen was found more distinct in the coarsening IGA, Widmanstätten austenite (WA) than the grain boundary austenite (GBA). The columnar epitaxial ferrite presented a strong <001> texture in the deposition direction, while the $\langle 001\rangle$ and $\langle 101\rangle$ orientations was found in the austenite. Random orientations of the intragranular secondary austenite was revealed. The Rotated Cube texture of the austenite grains were consumed by the "recrystallization" textures (Brass, Rotated Brass, Cu, R, E, and F) caused by the austenite reformation. The low-angle interphase boundaries between austenite and ferrite were predominated in the as-deposited wall, and, at which, the K-S orientation took the crucial part. A Taylor factor analysis revealed that through fabrication via additive process, the austenite became oriented "harder" and contributed most to good mechanical properties. The textured microstructure contributed about a $2.6 \%$ higher engineering strain in the $\mathrm{Z}$ direction and a $27.8 \mathrm{MPa}$ higher yield strength in the $\mathrm{X}$ direction.
\end{abstract}

Keywords: wire and arc additive manufacturing; super duplex stainless steel; element partitioning; texture and phase boundary orientations; Taylor factor 


\section{Introduction}

Duplex stainless steels (DSSs) contain usually 50\%/50\% austenite/ferrite phases which provided good mechanical properties with high corrosion resistance [1]. Since the early 1900s, DSSs have undergone rapid development owing to the increased understanding of $\mathrm{N}$ as a crucial alloying element. This significantly promoted the development of super DSSs (SDSSs). Currently, DSSs - particularly SDSSs - are widely used in the oil and gas pipelines, offshore structures, ocean machinery, chemical tanks, etc. [2].

From the traditional viewpoint, the manufacturing and processing of SDSS components are highly connected with two operations: casting and welding, and extensive studies have been conducted in this field [3-6]. With the rise of additive manufacturing technology [7], this type of material has seen vigorous development. From the open information, additive manufacturing of DSSs was first performed by Davidson [8] and Hengsbach [9] through selective laser melting (SLM). Porosity and an almost entirely ferritic microstructure were observed, and subsequent heat treatment was needed to obtain proper mechanical properties. Later, Davidson [10] focused on the metallurgical behavior during the SLM process. Epitaxial ferrite grains mainly grew along the build direction, and the growth direction of the austenite grains was affected around the cavities. Meanwhile, Posch [11] employed cold metal transfer (CMT) power as the heat source (CMT wire and arc additive manufacturing (WAAM)) and built a blade-like DSS component. Approximately $30 \%$ of the ferrite phase was observed in the asdeposited structure, and the porosity or lack of fusion was hardly found. This was confirmed by Eriksson [12] via the CMT method. The difference was that a ferrite content of $20 \%$ was observed in the latter study. This is mainly because of the different grade of the DSSs; ER2507 was used in the latter study. In addition to the phase content, Posch [11] reported that the ferrite grains presented the cube-on-cube texture; however, the austenite grains exhibited random orientations. Recently, Hosseini [13] and Hejripour [14] studied the cyclic thermal field during the WAAM process with DSSs and performed the corresponding microstructure characterizations, which provided vital information for recognizing and controlling the phase balance (50\%/50\% austenite/ferrite) during the WAAM process. Interestingly, Stützer [15] proposed a new solution for adjusting the austenite/ferrite ratio during WAAM deposition. The idea is to use an additional cold wire to change the $\mathrm{Cr}_{\mathrm{eq}} / \mathrm{Ni}_{\mathrm{eq}}$ value of the deposited metal. Thus, the austenite/ferrite ratio can be changed in the desired direction. In summary, the density, cyclic thermal field, microstructure, and mechanical properties of additive-manufacturing DSSs have been extensively studied by researchers, and some pioneering results were obtained. However, in contrast to melting electrode arc additive manufacturing, such as CMT WAAM and gas metal arc welding (GMAW) WAAM, non-melting electrode arc additive manufacturing with SDSSs, such as tungsten inert gas (TIG) WAAM, was conducted in our laboratory. In our previous study [16], with the subsequent layers, excessive growth of the austenite phase (coarsening GBA, WA and IGA, along with the propagation of the intragranular secondary austenite) was found in the wall-body area. As a result, high impact toughness was observed in this area. In this procedure, chromium nitrides assisted growth mechanism was found by the EBSD results.

According to the previous study, WAAM possesses great potential on the manufacturing of DSS parts with good mechanical properties and controllable microstructure. For the structural function integrated molding of large DSS parts, WAAM has unique advantages. Nevertheless, some essential details of the WAAM-made microstructure were not covered so far, such as the element redistribution during the TIG WAAM process and the crystallographic information of 
the as-deposited microstructure. Thus, further study was needed. Scanning electron microscopy (SEM) and energy-dispersive X-ray spectroscopy (EDX) were used to measure the element distribution in the printed material. Additionally, electron backscatter diffraction (EBSD) technology was employed to obtain the crystallographic information at the corresponding locations. After the analysis, the alloy element redistribution, grain orientation, texture, interphase boundary characterization, and Taylor/Schmid factors were examined and discussed.

\section{Material and methods}

A commercial ER2594 SDSS wire, provided by Voestalpine Böhler Welding Group, Austria was used. The chemical composition is shown in Table 1. The TOP-TIG arc melting method was used as the heat source. The manufacturing parameters are presented in Table 2.

Table 1

Chemical composition of the ER2594 wire (wt.\%).

\begin{tabular}{llllllllll}
\hline $\mathrm{C}$ & $\mathrm{Mn}$ & $\mathrm{W}$ & $\mathrm{Si}$ & $\mathrm{Cr}$ & $\mathrm{Ni}$ & $\mathrm{Mo}$ & $\mathrm{N}$ & $\mathrm{Cu}$ & $\mathrm{Fe}$ \\
\hline 0.02 & 1.08 & 0.60 & 0.39 & 25.98 & 10.09 & 3.09 & 0.22 & 0.80 & Balance \\
\hline
\end{tabular}

Table 2

Process parameters for the TOP-TIG WAAM manufacturing $(\eta=0.65$ [17]).

\begin{tabular}{ll}
\hline Electrode-to-workpiece distance & $3.5 \mathrm{~mm}$ \\
\hline Tungsten electrode tip angle & $22.5^{\circ}$ \\
\hline Deposition current $(I)$ & $185 \mathrm{~A}$ \\
\hline Deposition voltage $(U)$ & $13 \mathrm{~V}$ \\
\hline Arc Running Speed $(\boldsymbol{v})$ & $3 \mathrm{~mm} / \mathrm{s}$ \\
\hline Heat input $\left(\boldsymbol{Q}=\boldsymbol{\eta} \boldsymbol{U} \boldsymbol{I} \boldsymbol{v}^{-\mathbf{1}}\right)$ & $0.521 \mathrm{~kJ} / \mathrm{mm}$ \\
\hline Shielding gas and flow rate & Pure Ar; $15 \mathrm{~L} / \mathrm{min}$ \\
\hline Layer height & $0.8 \mathrm{~mm}$ \\
\hline Interpass temperature & $<100{ }^{\circ} \mathrm{C}$ \\
\hline
\end{tabular}

A single-pass multilayer program with the desired dimensions of $180 \times 125 \times 10 \mathrm{~mm}^{3}$ was used for deposition by a Fanuc welding robot system. The interpass temperature was measured by a thermometer. During the deposition, part of the feeding wire with the solidified droplet on the terminal was cut down and kept for the microstructure analysis. The sample extracting positions, a deposition schematic, and the coordinate system are shown in Fig. 1. The samples for metallographic assessments were ground half-automatically down to \#1000 and then polished with OPS solution $(0.05 \mu \mathrm{m})$ for 5-8 mins. After that, a $40 \mathrm{wt} . \% \mathrm{NaOH}$ solution was used to electrically etch the samples with a direct-current voltage of $3 \mathrm{~V}$ for 8-10 s until the sample surface became straw yellow. Optical analysis of the microstructure was performed with an Optiphot Nikon microscope, and then a Scanning Electron Microscope (SEM, FEI XL30-SFEG) equipped with the energy-dispersive spectrometry (EDS) detector was used to measure the elemental composition of the samples. For each kind of phase, at least three rectangular spectra were selected for average value and standard deviation calculation. After that, the samples were gradually ground down to \#4000 and polished by the OPS solution for 40 mins to largely remove the surface stress layer. Electro backscattered diffraction (EBSD) with a voltage of $20 \mathrm{kV}$ and a step length of $0.055-0.338 \mu \mathrm{m}$ was carried out by using an INCA 
Crystal EBSD system, Oxford Instruments. Crystallographic information was extracted using the Aztec acquisition software.

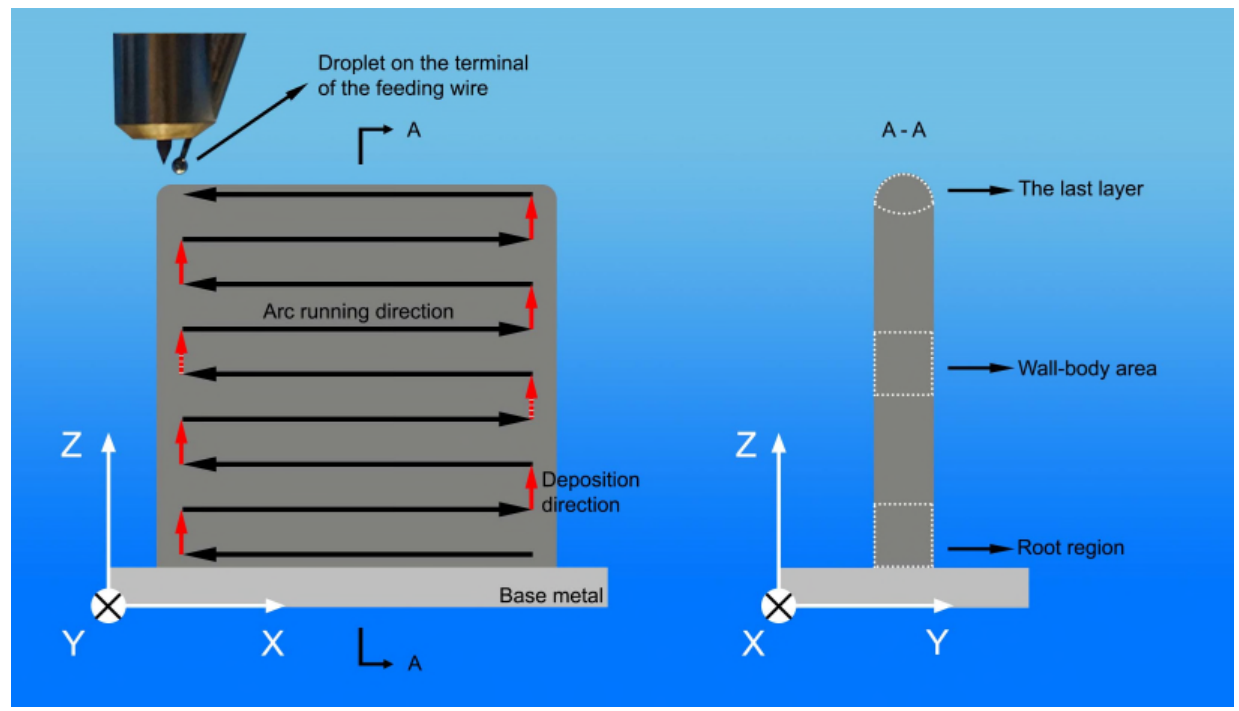

Fig.1 Schematic of the deposition process, the sample extraction positions, and the coordinate system.

\section{Results and discussion}

\subsection{Microstructure characterization and element partitioning}
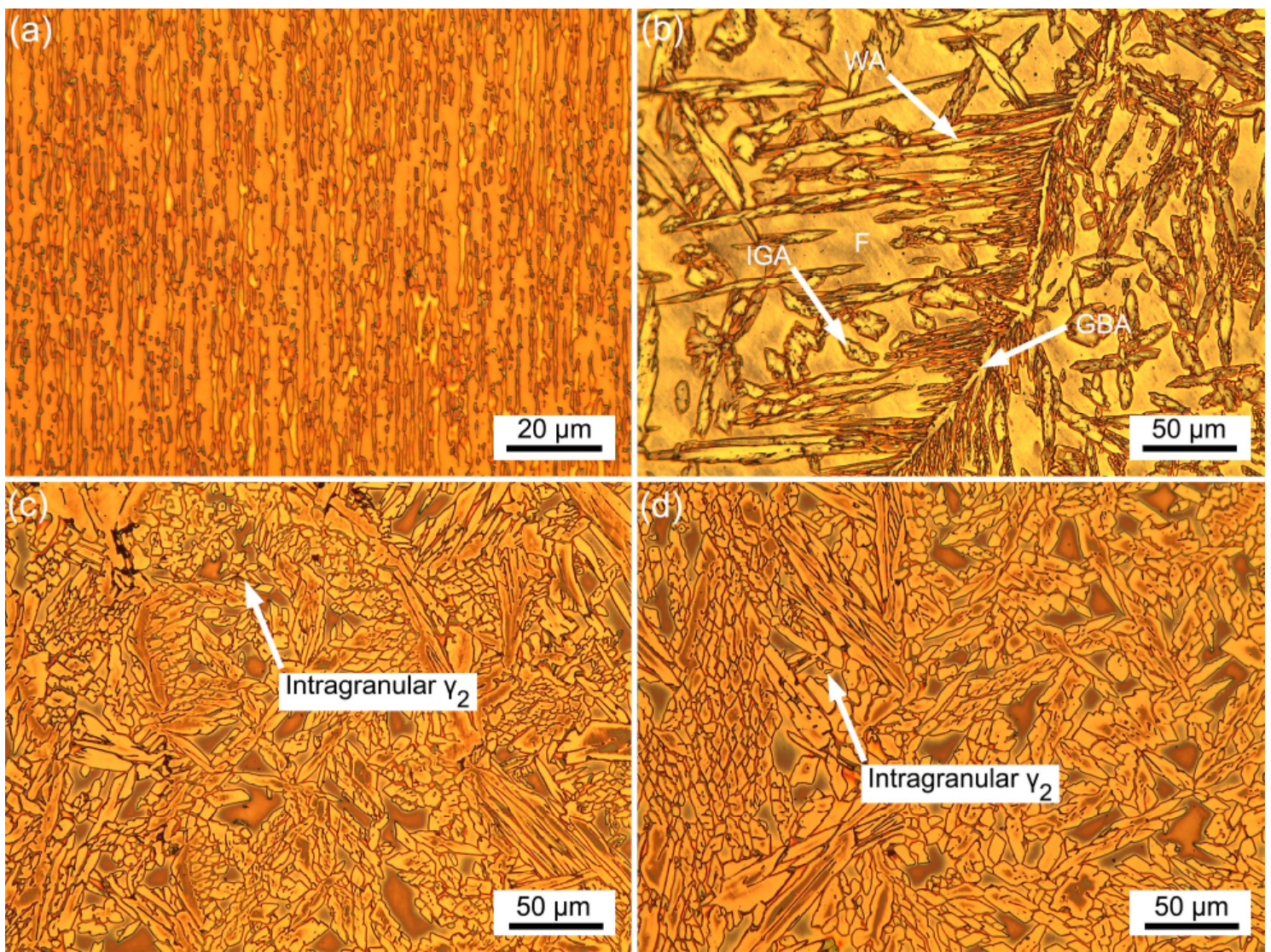

Fig. 2 Optical images of the wire base microstructure (a); (b), (c) and (d) present the microstructure in the last layer, the wall-body and root regions of the as-deposited wall, respectively. The microstructure in (b), 
(c) and (d) was taken from the YZ cross-section shown in Fig. 1.

The evolution process of the microstructure during the TOP TIG WAAM manufacturing is shown in Fig. 2, from the wire to the as-deposited wall. The microstructure of the as-received wire exhibited a typical band morphology (Fig. 2(a)). In the last layer, the microstructure suggests three type of formed austenite regions: grain-boundary austenite (GBA), Widmanstätten austenite (WA), and intragranular austenite (IGA). As reported by previous studies, cooling rate significantly affects the austenite content $[18,19]$ for the DSSs. In this case, as the feeding wire was primarily designed for welding SDSSs, more austenite formation elements ( $\mathrm{Ni}$ and $\mathrm{N}$ ) was added into the wire. The sensibility of austenite formation for the wire is more remarkable than the regular DSS feeding wires used by Hosseini[13] and Hejripour[14]. The microstructure in the solidified droplet revealed the easy formation of austenite for the feeding wire even solidified from high temperatures, as shown in Fig. 3. Hence, necessary local cooling was needed for this kind of material during the WAAM process. A drastic change of the microstructure in the wall-body and root regions was observed because of the "annealing" effect arising from the cyclic temperature fields (herein called the cyclic unsteady annealing effect (CUAE)) generated by the adjacent layers $[13,14]$. Under the CUAE, secondary austenite propagated in the form of IGA, intergranular secondary austenite (intergranular $\gamma 2$ ), and intragranular secondary austenite precipitation (intragranular $\gamma 2$ ). In addition to the secondary austenite, the coarsening of GBA, WA, and IGA also played crucial roles in the excessive growth of austenite. The coarsening mechanism as well as the generation of secondary austenite can be find in our previous work [16]. During the austenite reformation, element redistribution between austenite and ferrite is unavoidable.

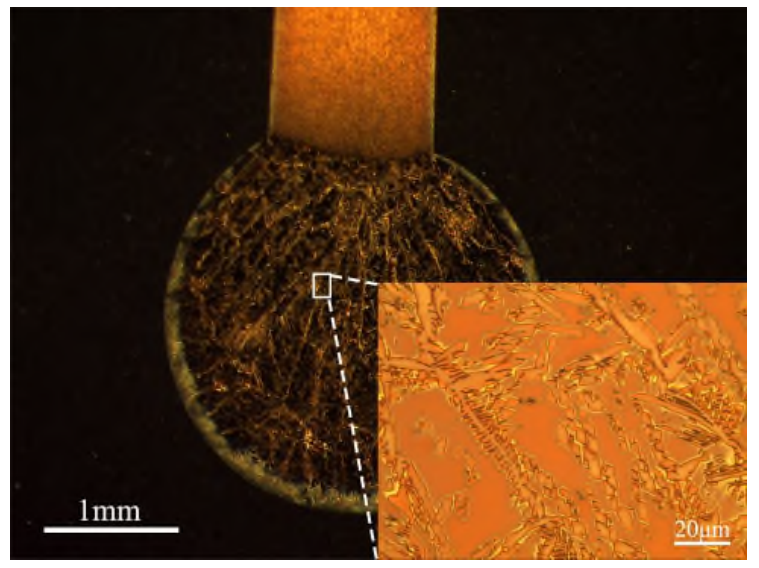

Fig. 3 Optical image of the solidified droplet macrotexture and the details in the white rectangle are shown in the embedded figure. 
(a)

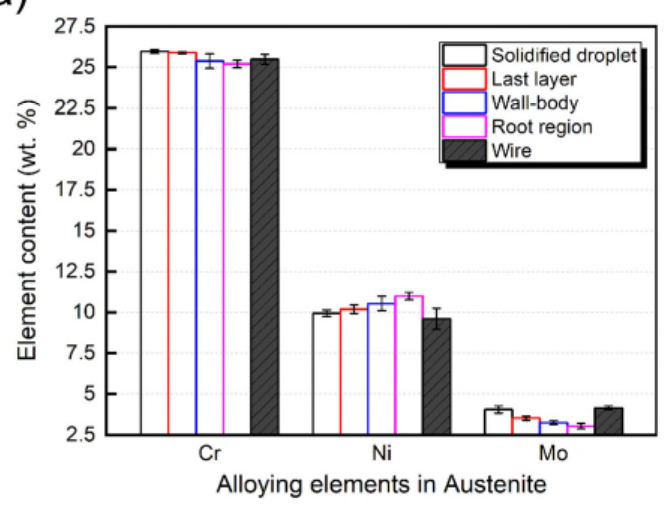

(b)

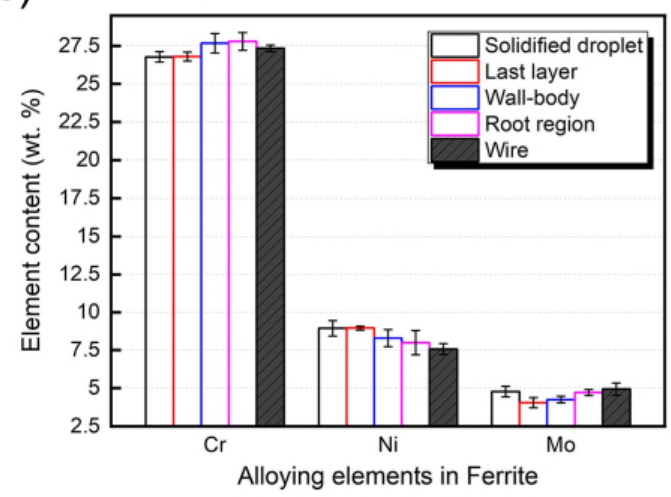

Fig. 4 Redistribution alloying elements (Cr, Ni, Mo) in the austenite (a) and ferrite (b) phases at different positions after additive fabrication, and their comparison to the raw material (wire). The error bars were calculated by the STDEV.P function in excel.

Partitioning of alloying elements between the ferrite and austenite phases not only affects the corrosion property[20] but also gives expression to the behavior of precipitations, such as the chromium nitrides[21] and sigma phase [22]. Fig. 4 shows the alloying elements in the austenite (a) and ferrite (b) phases, along with a comparison to the solidified droplet and wire. Partitioning of the alloying elements- $\mathrm{Cr}, \mathrm{Ni}$ and $\mathrm{Mo}-$ occurred in both the austenite and ferrite phases compared with the equilibrium condition (wire). Both the solidified droplet and the last layer cooled directly from the liquid state in a quick and un-equilibrium condition. As the composition in the liquid is homogeneous, the partitioning was largely suppressed. Hence, higher Mo and $\mathrm{Cr}$ contents, as well as lower Ni content, were observed in the austenite phase when compared to the wall-body and root region. Similar findings were also reported by Atamert and King [23] in the case of cooling from high temperatures (e.g., $1200{ }^{\circ} \mathrm{C}$ ). Mo showed more sensitivity to the cooling rate than $\mathrm{Cr}$ and $\mathrm{Ni}$. An obvious decrease of Mo content in austenite and ferrite was observed when compared with $\mathrm{Cr}$ and $\mathrm{Ni}$ due to higher cooling rate experienced in the solidified droplet. High cooling rates from high temperatures suppressed partitioning largely. The segregation tendency in austenite and ferrite was increased in the wallbody and root region. According to Ramirez and Lippold [21], the segregation of $\mathrm{Cr}, \mathrm{Ni}$, and Mo significantly depended on the cooling time and temperature. They found that, generally, as the reheating temperature and time increased, $\mathrm{Cr}$ and Mo were more likely to gather into the ferrite phase, while $\mathrm{Ni}$ was preferred in the austenite phase. The CUAE came with the adjacent layers during deposition provided the ideal conditions, as can be seen the work of Hejripour[14]. Hency, Ni content in the austenite phase increased from the last layer to the root region; nevertheless, the contents of $\mathrm{Cr}$ and Mo decreased in the austenite. The results agree well with the findings reported in [21]. 

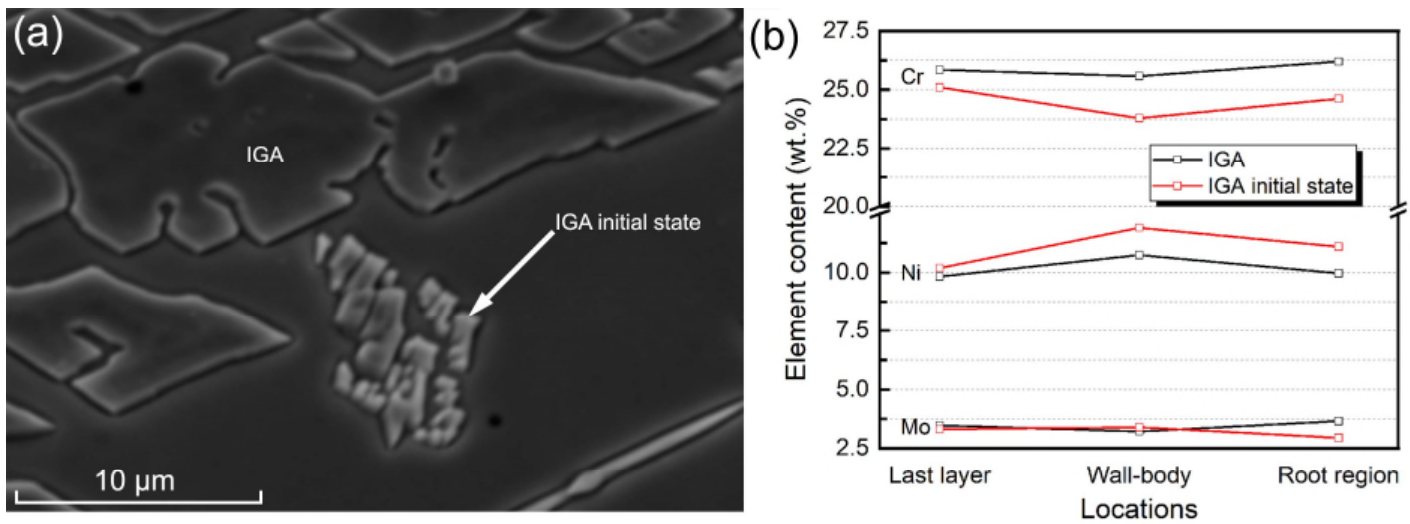

(c)

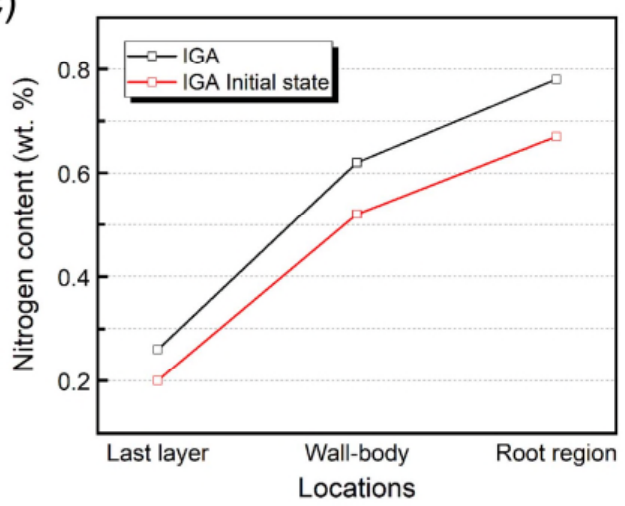

Fig. 5 (a) SEM image of the grown IGA and the initial state of IGA, along with the variation of $\mathrm{Cr}$, Ni and Mo (b), as well as the nitrogen (c) at these two locations.

Usually, the diffusion of elements is always associated with phase transformations. From our previous study [16] and the work of Hejripour[14] and Hosseini[13], in the wall-body and root region, coarsening Widmanstätten austenite and the growth of IGA was the major reason for the massive austenite content. Early reports from Zhang [24-26] found that Ni content was high at the IGA phase in different welding conditions, however, the reason for this phenomenon was not fully explained. In the present study, two states of the IGA: the grown IGA (IGA) and the initial state of IGA, were found, as shown in Fig. 5(a). The element distribution was shown in Fig. 5 (b) and (c). Ni content experienced a decrease stage during the growth process. Which means $\mathrm{Ni}$ rich regions played an important role in the nucleation of IGA. Considering the growth mechanism discussed in our previous work, areas around chromium nitrides can be acted as the nucleation sites. Another evidence comes from the growing $\mathrm{N}$ and $\mathrm{Cr}$ content in the IGA which caused by the dissolved chromium nitrides in the IGA [21]. Thus, the high Ni content in the IGA can be explained, as well as the prove of the transformation mechanism of IGA in the aspect of element partitioning. Similar situation can be expected in the Widmanstätten austenite and GBA, as shown by the nitrogen distribution in the GBA, WA and IGA in Fig. 6. The unregular distribution of the error bars came from the uneven nitrogen adsorption in the specimen surface and inherent equipment characteristics by using EDS, but this should not be a big problem for the tendency analysis [27]. Nitrogen in the WA and GBA both increased, which was highly connected with the chromium nitrides. From the average nitrogen distribution, IGA and coarsening WA were more sensitive to form than the coarsening of GBA, which can also be seen in Fig. 2 (c) and (d) where massive IGA and WA present. Hence, under the CUAE, nitrogen was more preferred gathering in IGA and WA resulting in 
the massive growth of IGA and coarsening WA.

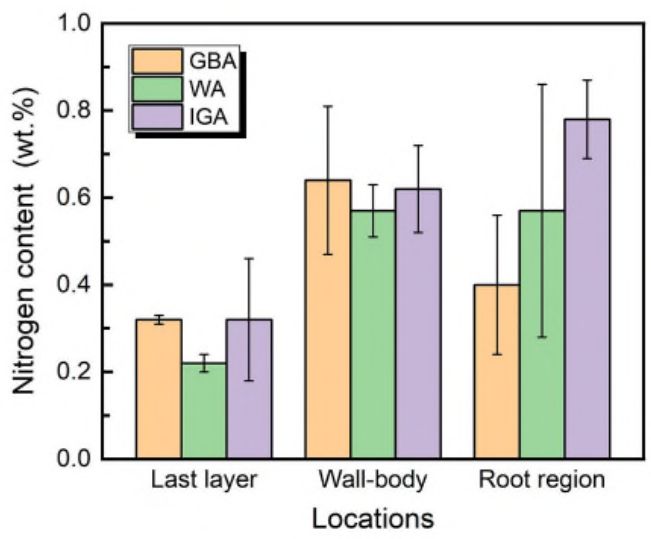

Fig. 6 Nitrogen content in GBA, WA and IGA at different locations in the as-deposited wall. Error bars were calculated by STDEV.P function in excel.

\subsection{Crystal orientation analysis}

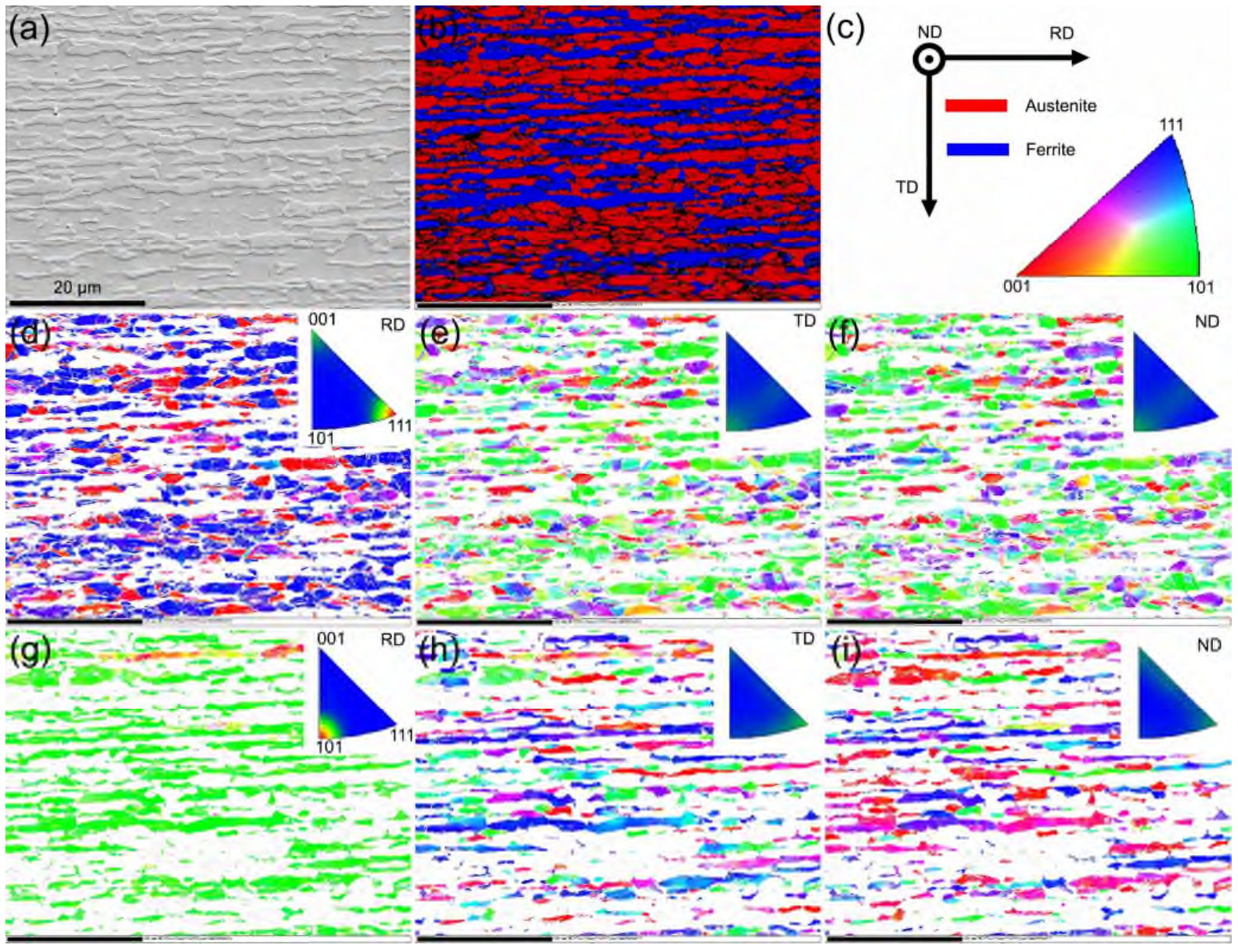

Fig.7 EBSD analysis of the wire used for printing: SEM image of the selected area (a); phase map showing the austenite in red and ferrite in blue (b); figure legend (c); IPF colored images of the austenite phase in the RD (d), TD (e), and ND (f); IPF colored images of the ferrite phase in the RD (g), TD (h), and ND (i). The [001] inverse pole figures of the IPF images were embedded on the top right of the corresponding figures. The index step was $0.0553 \mu \mathrm{m}$. 
Figs. 7-10 show the EBSD results. Most of the austenite grains in the wire were distributed along the $\langle 111>$ orientation in the RD and exhibited a typical fiber texture of $\langle 111>/ / \mathrm{RD}$. A strong $\alpha$ fiber texture $(<101>/ / \mathrm{RD})$ was observed in the ferrite grains, which were mostly present in the rolling base metals [28-30]. Figs. 8(a), 9(a), and 10(a) show that in the Z (deposition) direction, the austenite grains were mainly orientated along the $<001\rangle$ and $<101\rangle$ directions from the last layer to the root region. In the $\mathrm{Y}$ and $\mathrm{X}$ directions, the austenite grains exhibited a random distribution tendency in the form of multiple preferred orientations. A strong <001> texture of the ferrite phase was observed in the $\mathrm{Z}$ direction throughout the asdeposited wall. Meanwhile, some ferrite grains were orientated along the $<101>$ direction in the as-deposited wall in the $\mathrm{Z}$ direction and were mainly distributed on the interface of the austenite and ferrite phases. The $<101>$-orientated ferrite grains became more intensified in the wall-body area than that in the last layer in the $\mathrm{Z}$ direction. Because of the size of columnar ferrite grains, only several ferrite grains were detected. Consequently, the orientations of the ferrite grains in the $\mathrm{Y}$ and $\mathrm{X}$ directions were similar, as shown in Figs. 9(h) and 9(i). Besides, clear interface and orientation difference were shown in Fig. 8, 9 and 10 for the ferrite grains. The clear interface came from different ferrite grains in the observation field, also can be seen in $[29,30]$. The orientation difference was generated from two aspects: first, the ferrite grains present the columnar morphology, and grew from the root to the top, as reported in our previous study [16]. During solidification, the preferentially solidified columnar grains grew along the highest temperature gradient direction which was normal to the solid-liquid surface, as reported by [28]. Because of the free solidification surface on the bottom of the molten pool during deposition, most columnar grains showed some misorientations from the closest $<001\rangle / / \mathrm{Z}$ variation, as shown in Fig. 10 (g). Besides, this kind of misorientation between different ferrite grains was enlarged in the $\mathrm{Y}$ and $\mathrm{X}$ directions due to the rotation of reference frames. As a result, clear orientation difference was shown in Fig. 8,9 and 10 for the ferrite grains. Thus, the misalignment of external reference frame with respect to the maximum temperature gradient direction, along with different reference frames, was the main reason. Second, the cross-sectioning effect during sampling caused the different misorientation degree of the ferrite grains in the $\mathrm{Z}$ direction, as shown in Fig. $8(\mathrm{~g})$ and Fig. $10(\mathrm{~g})$. 


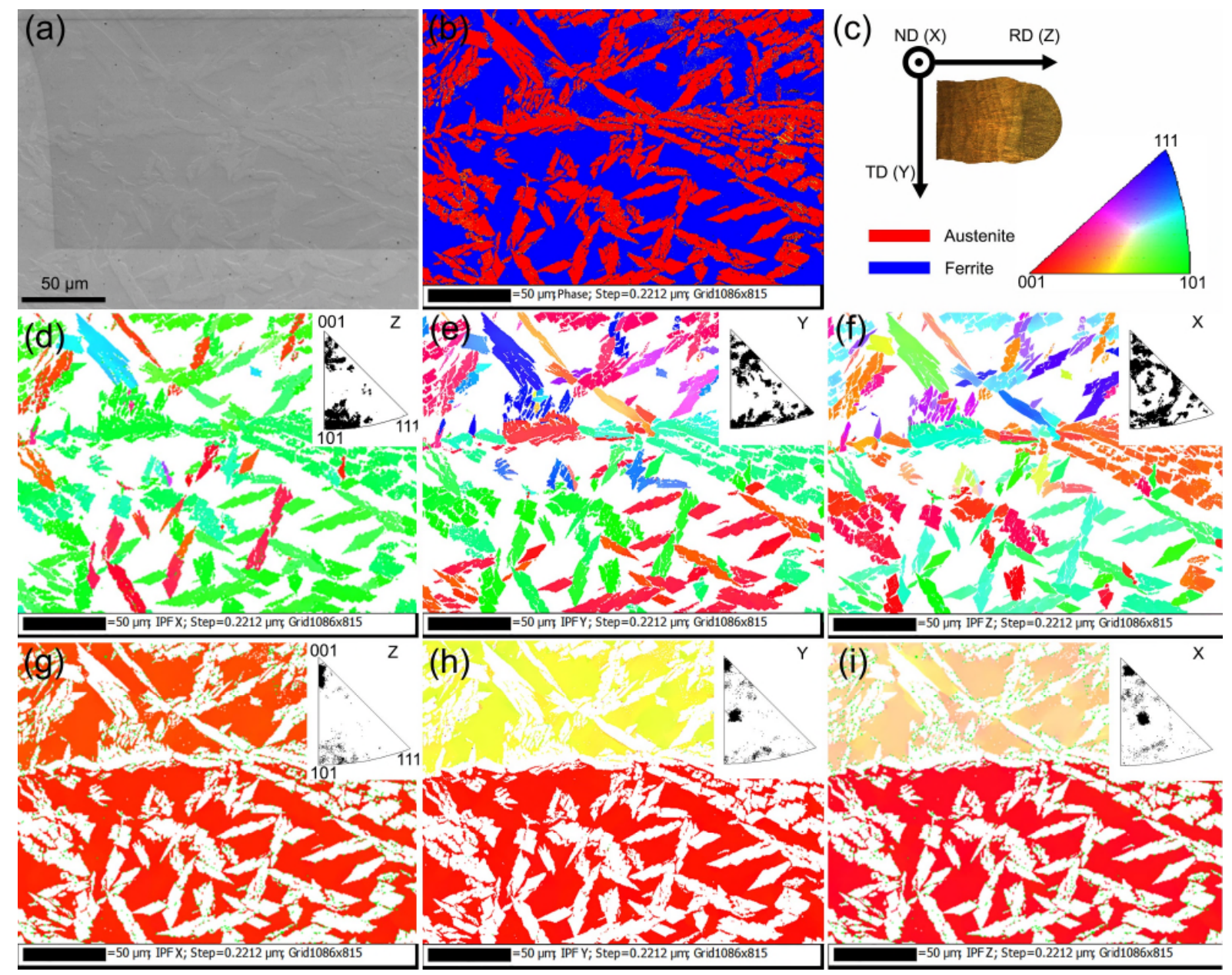

Fig. 8 EBSD images of the last layer: SEM image of the selected area (a); phase map presenting the austenite in red and ferrite in blue (b); figure legend and the relationship between the EBSD and deposition coordinate systems (c); IPF colored images of the austenite phase in the Z (d), Y (e), and X (f); IPF colored images of the ferrite phase in the $Z(g), Y(h)$, and $X(i)$. The [001] inverse pole figures of the IPF images were embedded on the top right of the corresponding figures. The index step was $0.2212 \mu \mathrm{m}$. 


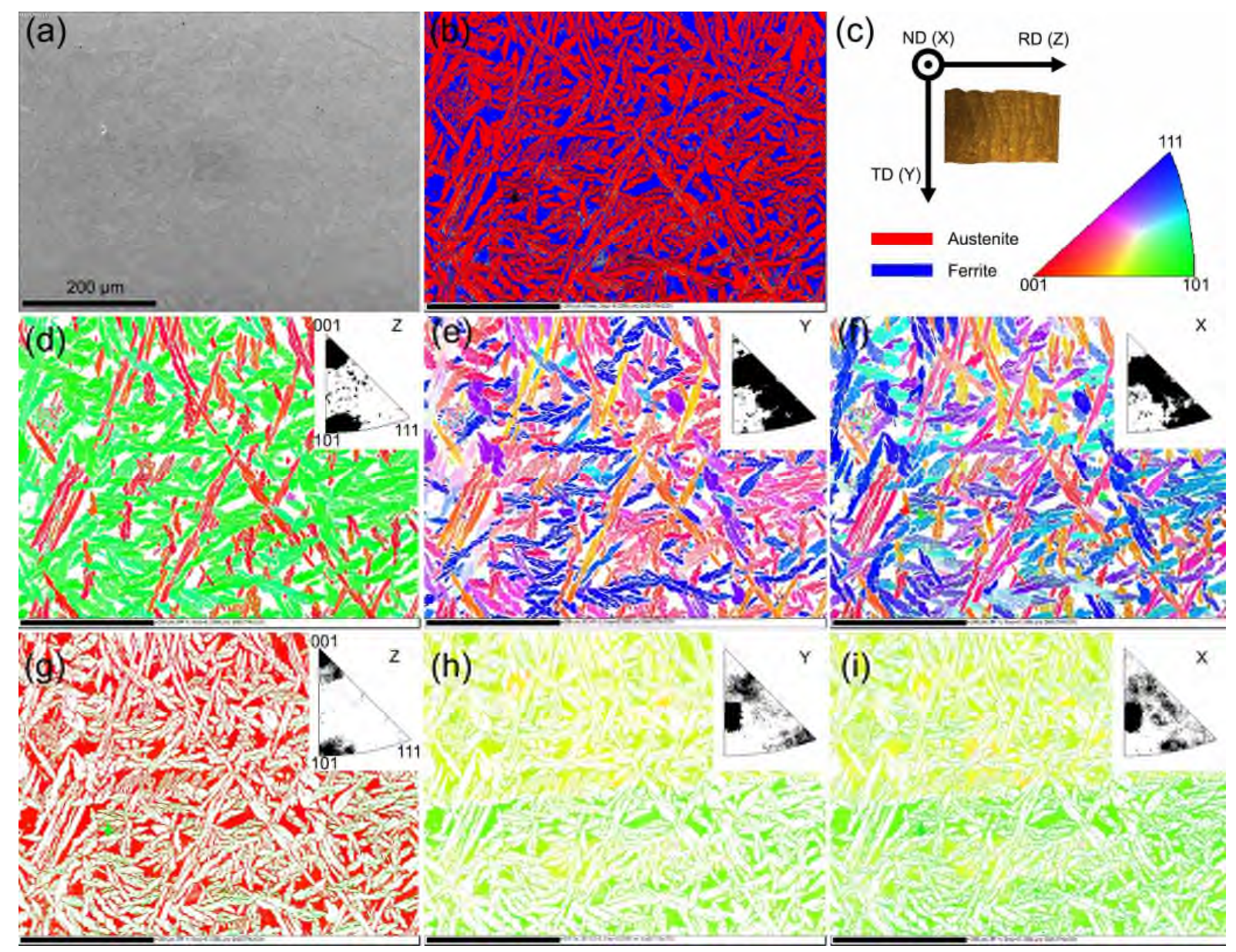

Fig. 9 EBSD images of the wall-body region: SEM image of the selected area (a); phase map presenting the austenite in red and ferrite in blue (b); figure legend and the relationship between the EBSD and deposition coordinate systems (c); IPF colored images of the austenite phase in the Z (d), Y (e), and X (f); IPF colored images of the ferrite phase in the Z (g), Y (h), and X (i). The [001] inverse pole figures of the IPF images were embedded on the top right of the corresponding figures. The index step was $0.3386 \mu \mathrm{m}$. 


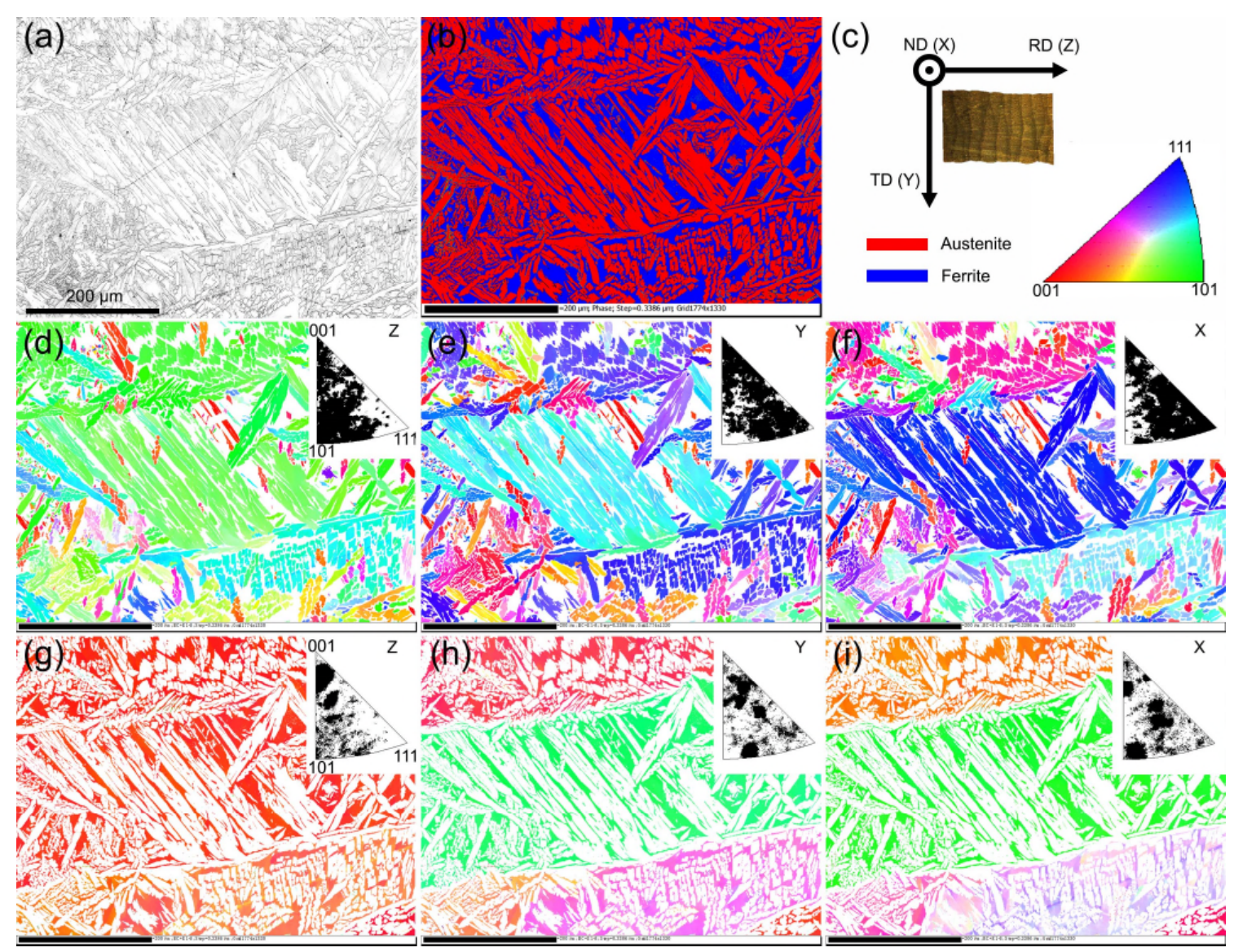

Fig. 10 EBSD images of the root region: SEM image of the selected area (a); phase map presenting the austenite in red and ferrite in blue (b); figure legend and the relationship between the EBSD and deposition coordinate system s (c); IPF colored images of the austenite phase in the Z (d), Y (e), and X (f); IPF colored images of the ferrite phase in the $\mathrm{Z}(\mathrm{g}), \mathrm{Y}(\mathrm{h})$, and $\mathrm{X}$ (i). The [001] inverse pole figures of the IPF images were embedded on the top right of the corresponding figures. The index step was $0.3386 \mu \mathrm{m}$.

Table 3

Texture intensity of austenite and ferrite grains in different locations. The values were obtained from the IPF images of the austenite and ferrite grains in different positions.

\begin{tabular}{ccccc}
\hline & Wire & Last layer & Wall-body & Root region \\
\hline Austenite & 16.05 & 5.81 & 7.83 & 5.24 \\
\hline Ferrite & 15.60 & 25.90 & 37.62 & 8.65 \\
\hline
\end{tabular}

Table 3 shows the texture intensity of the austenite grains in different locations. After deposition, the intensity of austenite grains decreased a lot, while the ferrite grains intensified largely. As discussed above, constrained direction growth of the columnar ferrite grains along $\mathrm{Z}$ direction was the main reason for the intensified texture. As reported by [31,32], random distributions of the austenite grains were naturally formed because they were generated from the "parent" ferrite phase, obeying a set of particular BCC-FCC ORs (called variants). In the last layer, during the parent (BCC)-product (FCC) transformation, many variants existed in each relationship because of the symmetry of cubic crystals [33]. For instance, there are 24 variants in K-S the relationship. Thus, the austenite texture intensity was presented as low as 5.81 in the last layer. Which means a large amount of primary austenite caused a lower texture 
intensity of the austenite phase. The CUAE accompanied by the subsequent layers caused a phase difference between the last layer and the wall-body. Consequently, a large amount of secondary austenite was generated. During this transformation, the product austenite phase inherited the textures from the parent ferrite phase [32]. This is why in the $\mathrm{Z}$ direction, most of the austenite grains were orientated along the $\langle 001\rangle$ and $\langle 101\rangle$ directions, as shown in Figs. 8(d) and 9(d). Accordingly, the texture intensity of the austenite grains was reinforced and increased from 5.81 in the last layer to 7.83 in the wall-body in the $\mathrm{Z}$ direction. In the root region, different heat transfer condition can be expected when compared with the wall-body area, as shown in Fig. 11. The substrate played a crucial role in heat conduction for the root region layers, while in the wall-body area, the smaller cross section of the as-deposited wall slightly restricted the heat conduction. As a result, more the primary austenite was saved under the CUAE in the root region. According to the previous analysis, more primary austenite leads to weaker texture intensity. Additionally, due to the sectioning effect, a certain amount of intragranular secondary austenite precipitation was captured. In contrast to the GBA, WA, and IGA, the intragranular $\gamma 2$ violated the inheritance rule. As shown in Fig. 12, the IGA and WA surrounded the intragranular $\gamma 2$. The IGA and WA obeyed the following rules: the $<101>$ orientation was observed in the IGA, and the $<001>$ orientation was observed in the WA in the $\mathrm{Z}$ direction, while, the intragranular $\gamma 2$ preferred multiple orientations. This inconsistency comes from the different growth mechanism of the intragranular c. As reported by Ramirez [21], chromium nitrides and oxide particles prefer to form the nucleus for the intragranular $\gamma 2$. Hence, the inheritance rules were broken, and weaker intensity was formed in this area. Finally, the weakest intensity was presented in the root region under the combined effect of these two aspects.

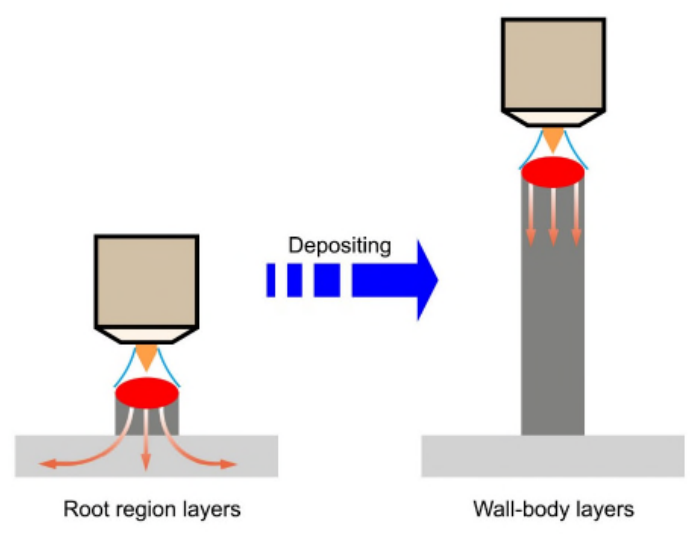

Fig. 11 Comparison of heat transfer condition in the root region layers and wall-body layers. In the root region, substrate acted as an effective thermal conductor. 


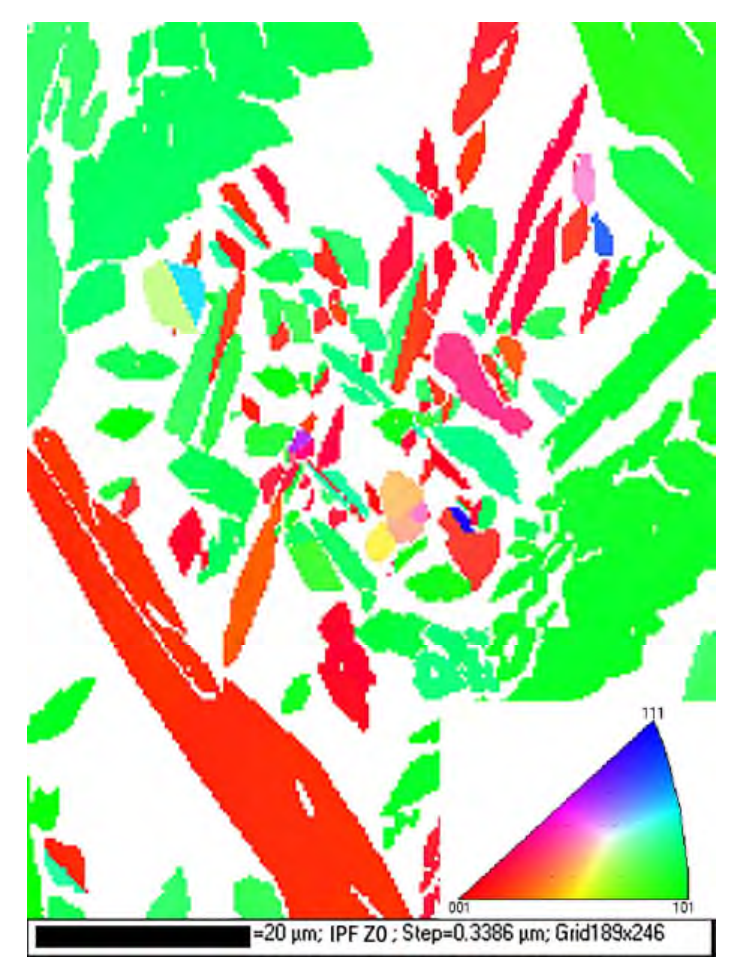

Fig. 12 IPF image of the intragranular $\gamma 2$ in the $Z$ direction, the legend of IPF was embedded on the bottom right of the figure, and the index step was $0.3386 \mu \mathrm{m}$.

\subsection{Texture analysis}

The preferred orientation of grains in a polycrystal determines the texture [34]. As reported by Bunge [35], in many cases, $20 \%-50 \%$ of the material properties, such as the strength, ductility, and plasticity, are affected by the texture. Fig. 13 shows the ideal texture locations at the corresponding $\varphi 2$ Euler angles. The definitions of the components in Fig. 13 are presented in Table 4. The texture evolution of the austenite phase throughout the process is shown in the ODF sections in Fig. 14. For the raw material, i.e., the feeding wire, typical deformation textures were observed as natural attributes of the fabrication process. The intensified $\{110\}<111>$ Rotated Brass texture, strong $\{112\}<111>\mathrm{Cu}$ component, and mild $\{123\}<634>$ $\mathrm{S}$ texture were the predominant texture components in the wire. A low-intensity Cube texture $\{001\}<100>$ and Goss $\{110\}<100>$ components adorned among the ODF sections. Previous studies performed by Milititsky [36] indicated that a high deformation strain resulted in strong Rotated Brass, $\mathrm{Cu}$ and Goss textures. Owing to the fabrication process, high strains were unavoidable, and the propagation of these deformation textures was reasonable. After melting and solidification, the deformation textures disappeared, and the casting and "recrystallization" textures were dominant. Herein case, the "recrystallization" texture mainly comes from the austenite reformation during ferrite/austenite transformation. It is generally believed that the directional growth of the crystal nucleus was compromised to the temperature gradient direction. For the BCC and FCC metals, both the rapid growth direction and the crystal axis are parallel to the $\langle 100\rangle$ direction during casting [37], welding [28,30,38], and additive manufacturing [11,39]. Close to the Rotated Cube $\{100\}<110>$ components were observed in the last layer. However, they were hardly observed in the wall-body and the root region. The strong $\mathrm{Cu}\{112\}<111>$ texture and the F component $\{111\}<112>$ were present in the wall-body, along with the weak R component $\{124\}<211>$. Meanwhile, a strong presence of the $\gamma$-fiber with the component which was close to the E component $\{111\}<110\rangle$ was observed in the root 
region. Liu [40] found that, during the annealing process of an $\mathrm{Al}$ alloy, the intensify of the Goss, Brass, $\mathrm{S}$, and $\mathrm{Cu}$ textures increased gradually, while that of the Cube texture decreased. This is called the evolution law of Cube textures and is considered to be related to the recrystallization [37]. Hence, it can be assumed that, with the austenite reformation under the CUAE, the original cube textures, the Rotated Cube texture components, were gradually consumed by the "recrystallization" textures (Brass, Rotated Brass, $\mathrm{Cu}, \mathrm{R}, \mathrm{E}$, and F). The EBSD results indicated the "recrystallization" frequency of the austenite phase in the last layer and the wall-body, as shown in Fig. 15. Clearly, a higher frequency of the "recrystallization" austenite phase was observed in the wall-body area. This proves that the "recrystallization" textures existed in the austenite phase under the CUAE.
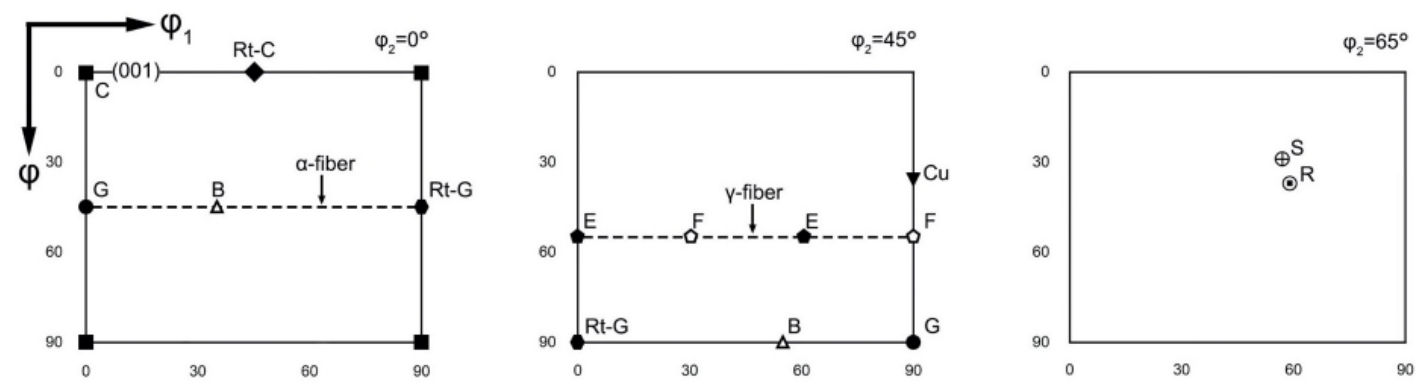

Fig. 13 Schematics of the ideal texture locations at the corresponding $\varphi_{2}$ Euler angles.

Table 4

Definitions of the texture components.

\begin{tabular}{lcc}
\hline Component & Miller Indices & Euler Angles $(\varphi 1, \varphi, \varphi 2)$ \\
\hline Cube (C) & $\{001\}<100>$ & $\left(0^{\circ}, 0^{\circ}, 0^{\circ}\right)$ \\
\hline Rotated Cube (Rt-C) & $\{001\}<110>$ & $\left(45^{\circ}, 0^{\circ}, 0^{\circ}\right)$ \\
\hline Goss (G) & $\{011\}<100>$ & $\left(90^{\circ}, 90^{\circ}, 45^{\circ}\right)$ \\
\hline Rotated Goss (Rt-G) & $\{110\}<110>$ & $\left(0^{\circ}, 90^{\circ}, 45^{\circ}\right)$ \\
\hline Brass (B) & $\{110\}<112>$ & $\left(55^{\circ}, 90^{\circ}, 45^{\circ}\right)$ \\
\hline E & $\{111\}<110>$ & $\left(0^{\circ} / 60^{\circ}, 55^{\circ}, 45^{\circ}\right)$ \\
\hline F & $\{111\}<112>$ & $\left(30^{\circ} / 90^{\circ}, 55^{\circ}, 45^{\circ}\right)$ \\
\hline Copper $(\mathrm{Cu})$ & $\{112\}<111>$ & $\left(90^{\circ}, 35^{\circ}, 45^{\circ}\right)$ \\
\hline S & $\{123\}<634>$ & $\left\{59^{\circ}, 37^{\circ}, 63^{\circ}\right\}$ \\
\hline R & $\{124\}<211>$ & $\left\{57^{\circ}, 29^{\circ}, 63^{\circ}\right\}$ \\
\hline
\end{tabular}



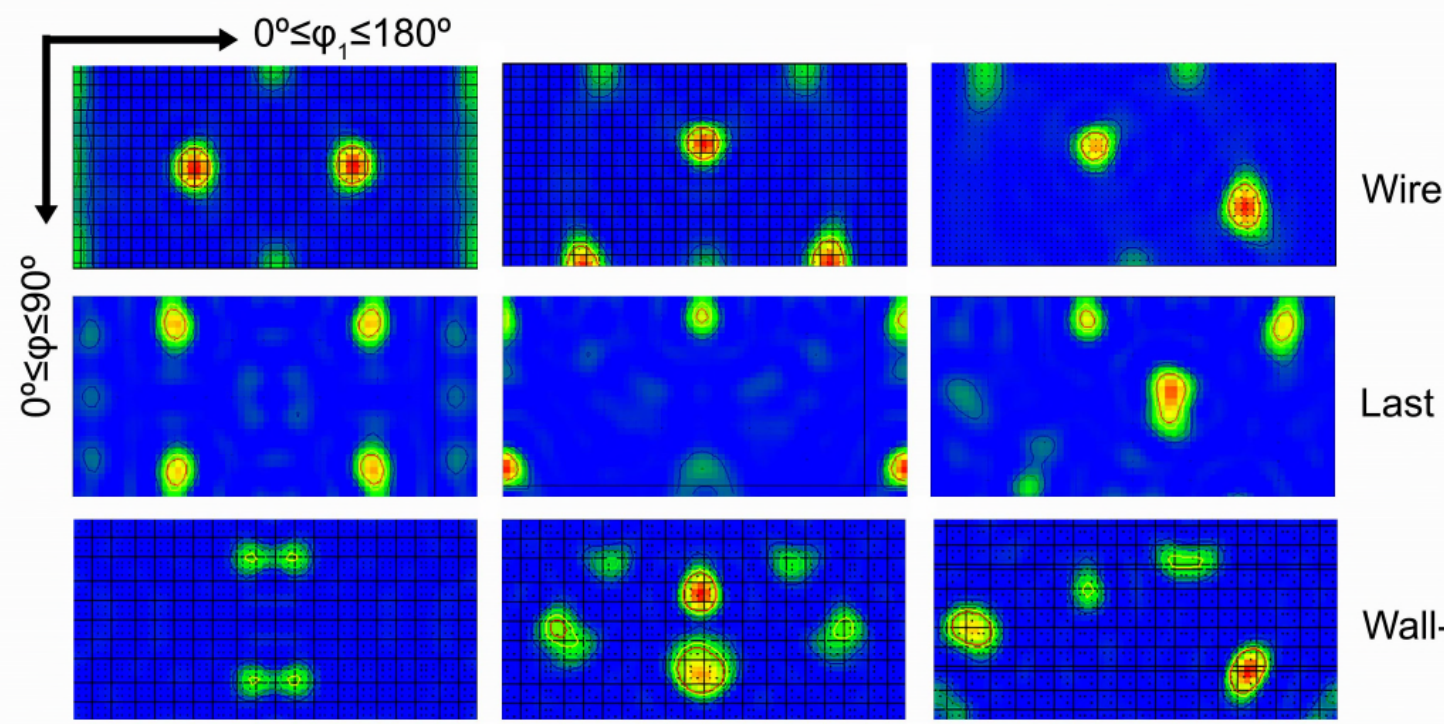

Last layer
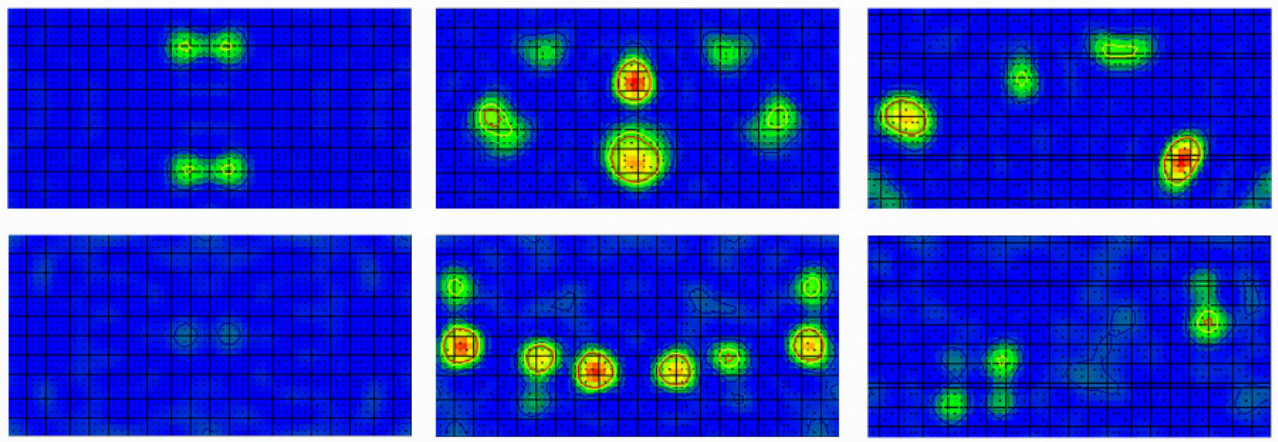

Wall-body
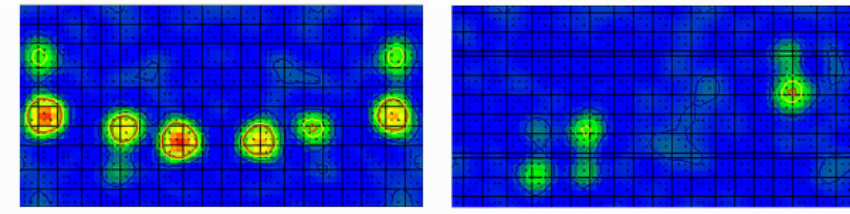

Root region

$\varphi_{2}=0$

$\varphi_{2}=45^{\circ}$

$\varphi_{2}=65^{\circ}$

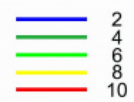

Fig. 14 ODF sections $\left(\varphi_{2}=0^{\circ}, \varphi_{2}=45^{\circ}, \varphi_{2}=65^{\circ}\right)$ of the austenite phase at different positions, from the wire base to the root region.
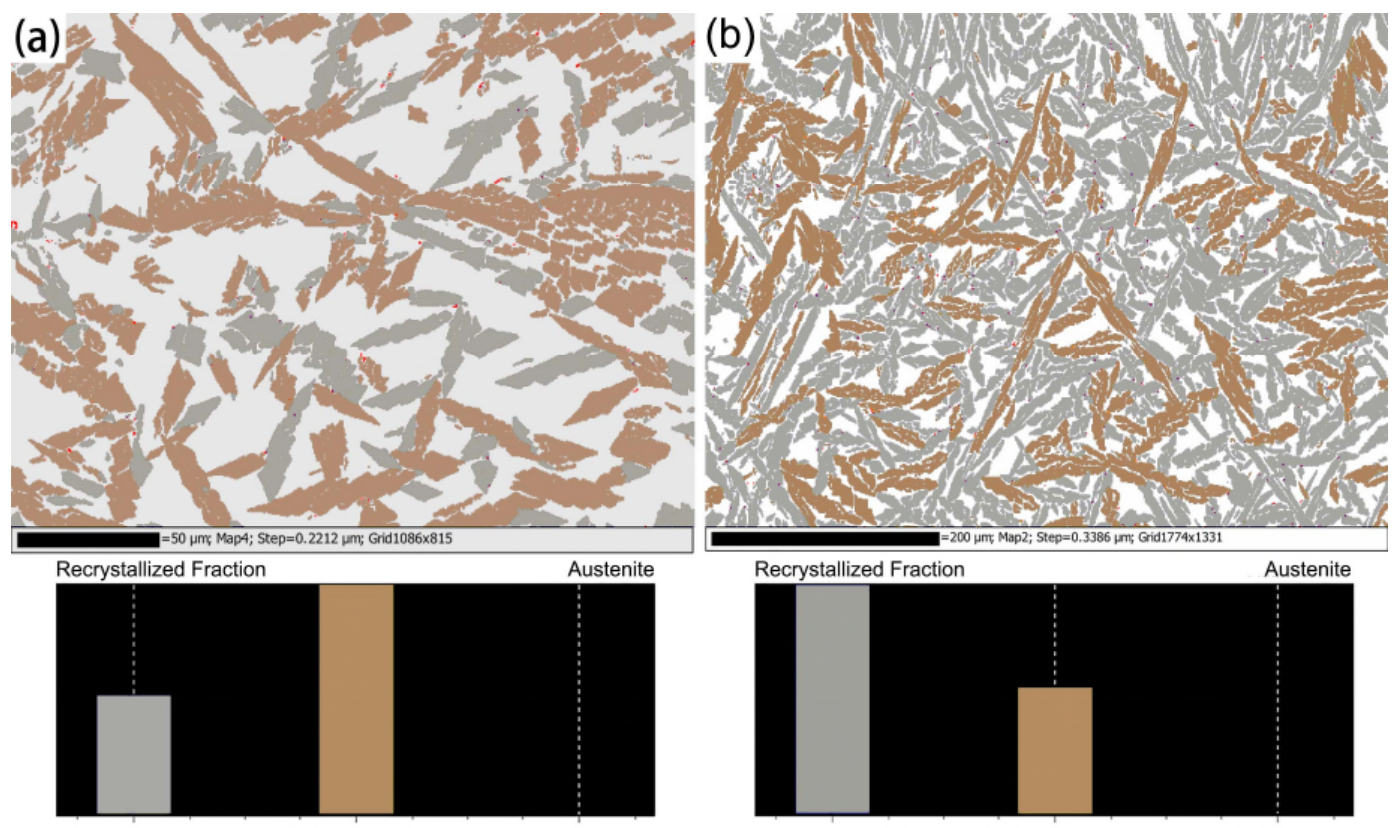

Fig. 15 Recrystallization and the corresponding fraction of the austenite phase in the last layer (a) and the wallbody positions (b) in the $\mathrm{Z}$ direction. 


\subsection{Interphase boundary analysis}
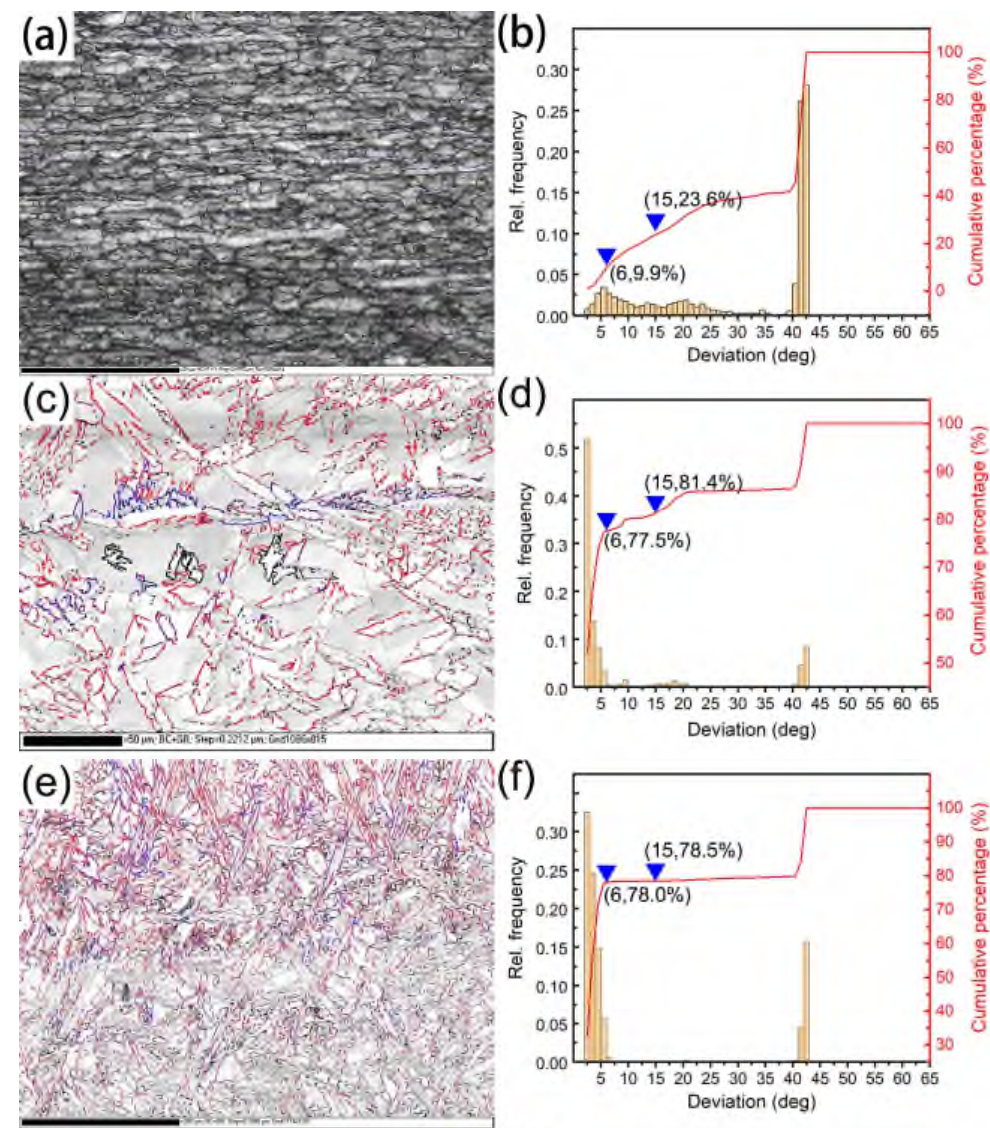

Deviation (deg)
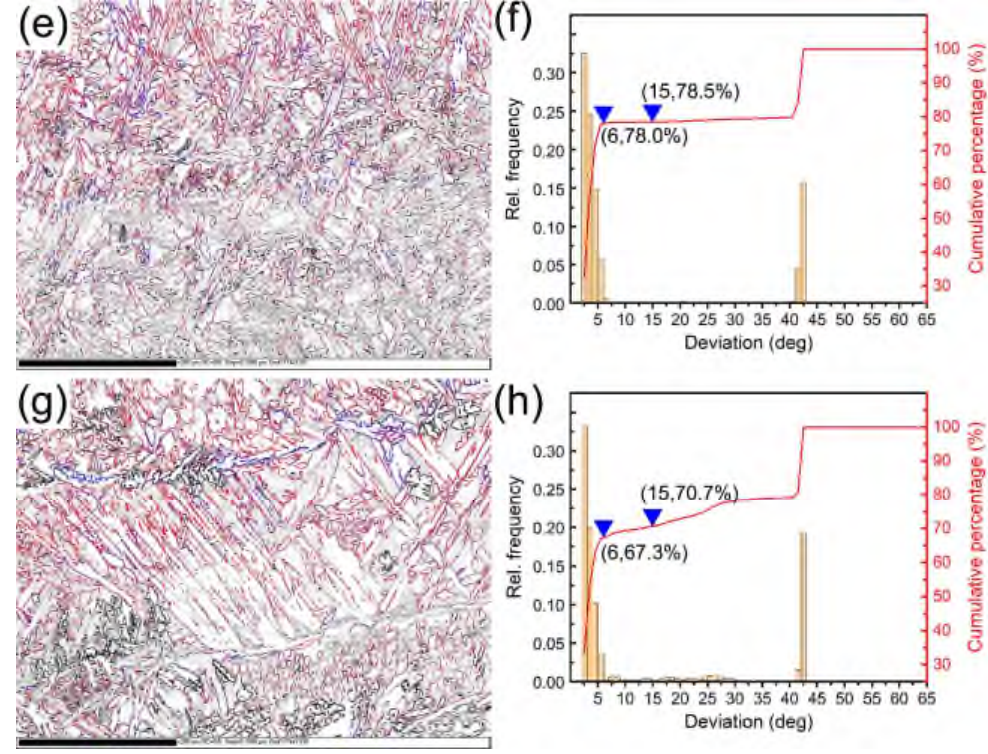

Fig. 16 OR boundaries between the austenite and ferrite phases of the wire base (a), the last layer (c), wallbody (e), and root region ( $\mathrm{g}$ ). The corresponding relative frequencies of the deviation angles are shown in (b), (d), (f), and (h), respectively. The deviation angles of the interphase boundaries were classified into three categories: $2^{\circ}-6^{\circ}$ (red), $6^{\circ}-15^{\circ}$ (blue), and $>15^{\circ}$ (black).

The interphase boundaries of the austenite and ferrite phases played an important role on the properties of the DSSs, such as the crack initiation [41] and corrosion resistance [42]. According to the deviation angle between the two adjacent austenite and ferrite phases, there were two types of interphase boundary: low-angle $\left(2^{\circ}-15^{\circ}\right)$ interphase boundary (LAIB) and high-angle $\left(>15^{\circ}\right)$ interphase boundary (HAIB). As shown in Fig. 16, the HAIB was predominant $(76.4 \%)$ in the wire. The LAIB took the majority in the as-deposited wall with the values of $81.4 \%$ in the last layer, $78.5 \%$ in the wall-body, and $70.7 \%$ in the root region. Fine recrystallization grains in the wire contribute most to the HAIBs. After melting and solidification through the WAAM process, columnar ferrite grains and austenite phases took the place of the fine grains. As a result, the HAIBs was replaced by the LAIBs in the as- 
deposited wall. The LAIBs were mainly observed between GBA, WA, and the ferrite matrix. The IGA contributed to both the LAIB and HAIB, as shown in Figs. 16(e) and (g). As previously mentioned, during the BCC-FCC transformation, some variants were selected according to different ORs. The KS OR was mostly found by researchers in DSS weldments [38,43-45]. Generally, the KS OR of the austenite/ferrite interphases follows a coherent or semi-coherent interphase. However, the exact KS OR is unlikely to exist. According to the studies performed by Karlsson and Börjesson [43], the phase boundaries within $6^{\circ}$ were classified as special phase boundaries (close to the KS OR). Hence, the LAIB here was mainly dominated by the special phase boundaries, which were close to the KS OR. As shown in Figs. 16(c) and (g), the interphase boundaries between WA and the surrounding ferrite matrix were close to the KS OR, whereas the GBA had an OR close to KS with one of the adjacent ferrite grains and a random OR with the other. The reason for the nonidentical ORs between the WA and GBA was explained by Menezes et al. [43] with the assumption of different transformation mechanisms of these two forms of austenite. The OR of the IGA in the weldments was investigated by Karlsson and Börjesson [43]. They found that the coarsening IGA was often close to KS, while the finest IGA was mainly randomly oriented. This tendency was also observed in the present study. As shown in Fig. 16(c), the close-to-KS OR and LAIBs dominated the coarsening IGA, whereas the fine IGA was surrounded by the HAIBs. Owing to the nature of coherent boundaries, an easy crack path can be expected along the KS OR, which is a disadvantage for the hot-workability [46]. However, because the LAIB provides excellent resistance to the interphase cracking, better impact toughness in the wall-body can be expected than that in the root region, which was supported by our previous study [16].

\subsection{Taylor factor and Schmid factor}

(a)

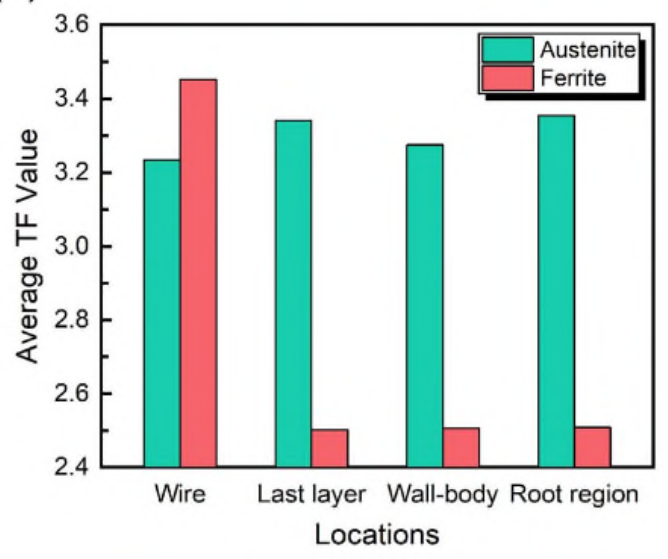

(b)

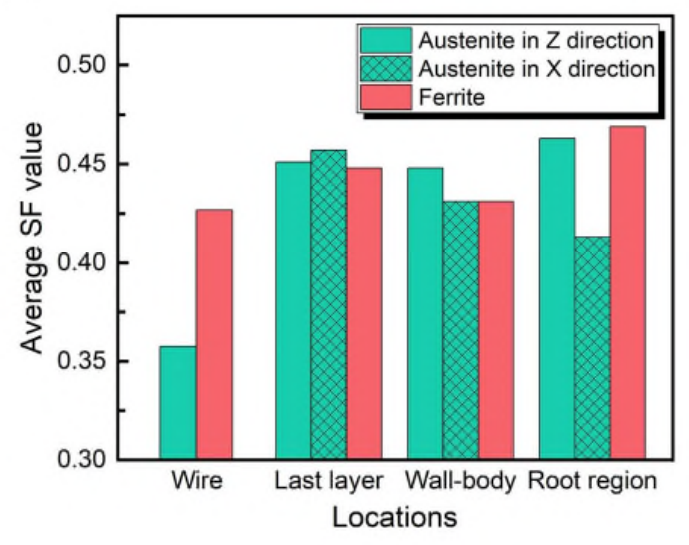

Fig. 17 Average Taylor factor (a) and Schmid factor (b) values of the austenite and ferrite phases at different locations.

The Taylor factor (TF) represents for the orientation hardness, i.e., the resistant ability to the plastic deformation of crystals. According to Schmid's law, with a larger SF, the slip plan operates more easily when a force is applied, and the grain is "softer". Owing to the reciprocal relationship between the SF and TF (although it cannot exactly correspond to the SF calculation for a given grain [37]), a higher SF usually results in a lower TF. Generally, higher TF values are associated with a higher yield strength, indicating that the grain is "harder" [47]. Fig. 17 
shows the distribution of the TF and SF values of the austenite and ferrite phases at different locations. The TF for the ferrite phase in the wire was 3.452, and the TF decreased rapidly to 2.505 in the last layer and kept almost unchanged in the wall-body and root region. Directional growth of the columnar ferrite grains took the main responsibility for the stable TF values. A slight fluctuation of the TF values around 3.25 for the austenite grains was revealed from the last layer to the root region. For this material, after the WAAM process, austenite contributed most to the yield stress. Considering the TF values experienced a decrease in the wall-body and a mild increase in the root region. From the above analysis, it can be seen that the coarsening Widmanstätten austenite and IGA made the austenite phase "soft", however, the intragranular $\gamma 2$ made it "hard". Hence, some necessary local cooling measures were needed to accelerate the cooling rate in the temperature range of $500-800{ }^{\circ} \mathrm{C}$ where both of the Widmanstätten austenite and IGA preferred to grow, as reported by Yang[48]. In general, after the WAAM manufacturing, the ferrite phase became "softer," while the austenite phase became a little "harder."

Table 5 Engineering strain/stress of the tensile samples in $\mathrm{Z}$ and $\mathrm{X}$ directions, along with the comparison of the ASTM standard sample. Results came from our previous work[16].

\begin{tabular}{cccc}
\hline & Z direction & X direction & ASTM A 890 \\
\hline Engineering strain (\%) & $36.4 \pm 1.2$ & $33.8 \pm 1.1$ & 25 \\
\hline Engineering stress $(\mathrm{MPa})$ & $519.9 \pm 19.3$ & $547.7 \pm 18.4$ & 450 \\
\hline
\end{tabular}

The SF values of the columnar ferrite grains were around 0.458 which was slightly higher than that in the wire (0.441). "Soft" oriented ferrite grains were obtained through the WAAM process. For the austenite phase, after deposition, more easy-to-deform grains can be expected as the obvious increasement of the SF values was present. Hence, the high ductility, contributed from both of the austenite and ferrite phases, of the deposited material can be expected, as shown in Table 5. In the as-deposited wall, more "soft" oriented austenite grains were observed in $\mathrm{Z}$ direction than that in the $\mathrm{X}$ direction according to the variance of the SF values in these two directions. This resulted $2.6 \%$ increasement of elongation in the $\mathrm{Z}$ direction, as shown in Table 5. To elucidate the nature of this difference, the SF distribution of austenite grains in the $\mathrm{X}$ direction is presented in Fig. 18. Three camps of grain orientations were observed and presented in different colors. The higher- and lower- SF grains are shown in red and green, respectively. Three spots were extracted for a three-dimensional view of the grain orientations, along with their SF values. Spot 1 had an SF of 0.5. According to Schmid's law, the angle between the tension direction and the slip direction, , can be determined as $45^{\circ}$. Similarly, $\lambda$ was calculated as approximately $28.6^{\circ}$ and $17.7^{\circ}$ for spots 2 and 3 , respectively. A smaller $\lambda$ indicated that more stress was needed to reach the critical stress (a specific value for a given material). From Table 5, the extra stress was around 27.8 MPa in the X direction. 


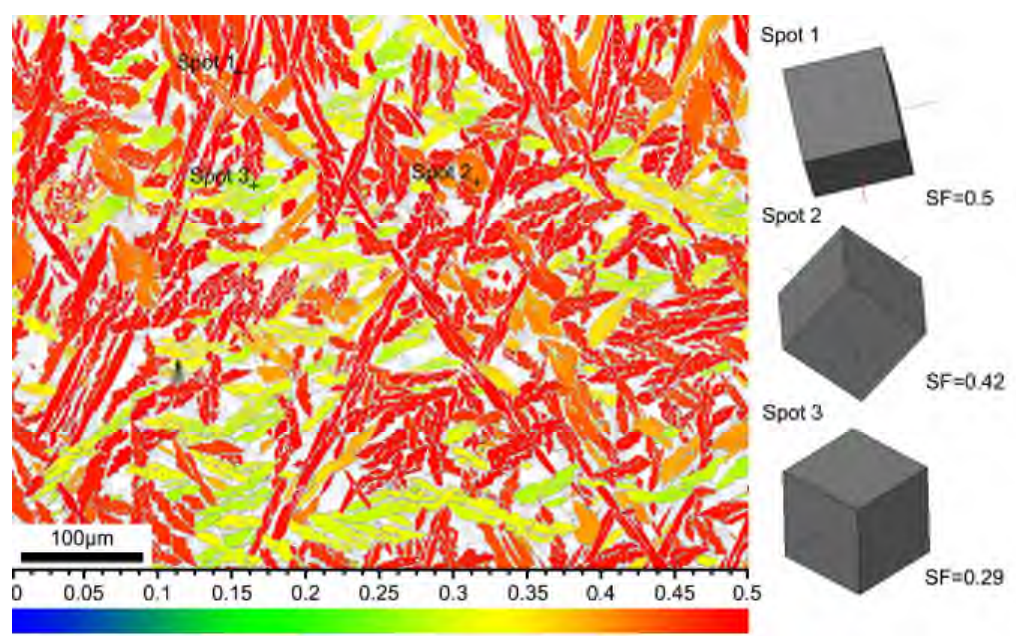

Fig. 18 SF distribution of the austenite phase in the wall-body area under the following assumption: 1), the active slip system is $[111]<1 \overline{10}>$; 2 ), the applied stress direction is parallel to the $\mathrm{X}$ direction.

\section{Conclusion}

- When the austenite nucleates at high temperatures, its composition is similar to that of the ferrite phase, and the segregation is limited. Owing to the CUAE accompanied by the subsequent layers, the austenite stabilizer $(\mathrm{Ni})$ was preferred to concentrate in the austenite phase, and vice versa for the ferrite stabilizer (Cr, Mo).

- Chromium nitrides assisted growth of the IGA was confirmed by the higher Ni, but, lower $\mathrm{Cr}$ and $\mathrm{N}$ observed in the IGA initial state. In the wall-body, nitrogen was more preferred in the coarsening IGA as well as the Widmanstätten austenite.

- The austenite phase presented $\langle 001\rangle$ and $\langle 101\rangle$ orientations in the $\mathrm{Z}$ direction of the asdeposited wall. While, multiple preferred orientations were observed in the $\mathrm{X}$ direction. The ferrite columnar grains showed $<001>$ Cube texture in the as-deposited wall.

- In the wall-body area, with the coarsening of the primary austenite and the reformation process under the CUAE, the Rotated Cube texture $(\{100\}<110\rangle)$ was consumed gradually by the "recrystallization" textures (Brass, Rotated Brass, Cu, R, E and F).

- The LAIBs dominated in the as-deposited wall from the last layer to the root region. The specific phase boundary, with the K-S OR, took the central part of the interphase boundaries.

- After fabrication, the austenite phase became oriented "harder", and contributed most to the yield stress. The high ductility of the printed material came from the easy-to-deform grains provided by both of the austenite and ferrite phases.

\section{Acknowledgements}

This work was supported by the Nanjing University of Science and Technology Scholarship (No. AE91309) and National Natural Science Foundation of China (No. 51805266). The authors express gratitude to the technician members of the Welding Engineering and Laser Processing Centre, Cranfield University, as well as, Dr. Xianwei Liu for the assistance during the SEM and EBSD analyses.

Conflicts of Interest: The authors declare no conflicts of interest. 


\section{Data availability:}

The raw/processed data required to reproduce these findings cannot be shared at this time as the data also forms part of an ongoing study.

\section{Reference}

[1] J.C. Lippold, D.J. Kotecki, Welding Metallurgy and Weldability of Stainless Steel, John Wiley \& Sons, USA, 2014.

[2] A. Vinoth Jebaraj, L. Ajaykumar, C.R. Deepak, K.V. Aditya, Weldability, machinability and surfacing of commercial duplex stainless steel AISI2205 for marine applications - A recent review, J. Adv. Res. 8 (2017) 183-199.

[3] S.Q. Wen, Metallurgical Evaluation of Cast Duplex Stainless Steels and Their Weldments, University of Tennessee, 2001.

[4] G. Mohammed, M. Ishak, S. Aqida, H. Abdulhadi, Effects of Heat Input on Microstructure, Corrosion and Mechanical Characteristics of Welded Austenitic and Duplex Stainless Steels: A Review, Metals 7 (2017).

[5] B. Varbai, Y. Adonyi, R. Baumer, T. Pickle, J. Dobranszky, K. Majlinger, Weldability of Duplex Stainless Steels - Thermal Cycle and Nitrogen Effects, Welding J. 98 (2019) 78-87.

[6] A. Pramanik, G. Littlefair, A. K. Basak, Weldability of Duplex Stainless Steel, Mater. Manuf. Process. 30 (2015) 1053-1068.

[7] I.Gibson, D. Rosen, B. Stucker, Additive Manufacturing Technologies: 3D Printing, Rapid Prototyping, and Direct Digital Manufacturing, Springer Science+Business Media, New York, 2015.

[8] S. Singamneni K. Davidson, Selective Laser Melting of Duplex Stainless Steel Powders: An Investigation, Mater. Manuf. Process. 31 (2015) 1543-1555.

[9] F. Hengsbach, P. Koppa, K. Duschik, M.J. Holzweissig, M. Burns, J. Nellesen, W.Tillmann, T. Tröster, K.P. Hoyer, M. Schaper, Duplex stainless steel fabricated by selective laser melting - Microstructural and mechanical properties, Mater. Des. 133 (2017) 136-142.

[10] K.P. Davidson, S.B. Singamneni, Metallographic evaluation of duplex stainless steel powders processed by selective laser melting, Rapid Prototyping J. 23 (2017) 1146-1163.

[11] G. Posch, K. Chladil, H. Chladil, Material properties of CMT-metal additive manufactured duplex stainless steel blade-like geometries, Weld. World 61 (2017) 873-882. [12] M. Eriksson, M. Lervåg, C. Sørensen, A. Robertstad, B.M. Bård, B. Nyhus, R. Aune, X.B. Ren, O.M. Akselsen, Additive manufacture of superduplex stainless steel using WAAM, MATEC Web of Conferences 188 (2018) 03014-.

[13] V. A Hosseini, M. Högström, K. Hurtig, M.A. Valiente Bermejo, Lars-Erik Stridh, L. Karlsson, Wire-arc additive manufacturing of a duplex stainless steel: thermal cycle analysis and microstructure characterization, Weld. World 63 (2019) 975-987.

[14] F. Hejripour, F. Binesh, M. Hebel, D.K. Aidun, Thermal modeling and characterization of wire arc additive manufactured duplex stainless steel, J. Mater. Process. Technol. 272 (2019) 58-71.

[15] J. Stützer, T. Totzauer, B. Wittig, M. Zinke, S. Jüttner, GMAW Cold Wire Technology for Adjusting the Ferrite-Austenite Ratio of Wire and Arc Additive Manufactured Duplex Stainless Steel Components, Metals 9 (2019).

[16] X.Y. Zhang, K.H. Wang, Q. Zhou, J.L. Ding, S. Ganguly, G. Marzio, D.Q. Yang, X.F. Xu, P. Dirisu, S.W. Williams, Microstructure and mechanical properties of TOP-TIG-wire and arc additive manufactured super duplex stainless steel (ER2594), Mater. Sci. Eng. A 762 (2019). 
[17] C.S. Wu, Welding Thermal Processes and Weld Pool Behaviour, CRC Press, 2011.

[18] Henrik Sieurin, Rolf Sandström, Austenite reformation in the heat-affected zone of duplex stainless steel 2205, Mater. Sci. Eng. A 418 (2006) 250-256.

[19] F. Tehovnik, B. Arzensek, B. Arh, D. Skobir, B. Pirnar, B. Zuzek, Microstructure evolution in SAF 2507 super duplex stainless steel, Mater. Technol. 45 (2011) 339-345.

[20] Z.Q. Zhang, H.Y. Jing, L.Y. Xu, Y.D.Han, L. Zhao, J.L. Zhang, Influence of microstructure and elemental partitioning on pitting corrosion resistance of duplex stainless steel welding joints, Appl. Surf. Sci. 394 (2017) 297-314.

[21] A.J. Ramirez, J.C. Lippold, S.D. Brandi, The Relationship between Chromium Nitride and Secondary Austenite Precipitation in Duplex Stainless Steels, Metall. Trans. A 34A (2003) $1575-1597$.

[22] R.A. Farrar, The Importance of Microstructural Transformations for Welding and the Stability of Long Term Service Properties, Weld. World 36 (1995) 143-151.

[23] S. Atamert, Super duplex stainless steels Part 1 Heat affected zone microstructures, Mater. Sci. Tech. 8 (1992) 896-911.

[24] Z.Q. Zhang, H.Y. Jing, L.Y. Xu, Y.D. Han, L. Zhao, C. Zhou, Effects of nitrogen in shielding gas on microstructure evolution and localized corrosion behavior of duplex stainless steel welding joint, Appl. Surf. Sci. 404 (2017) 110-128.

[25] Z.Q. Zhang, H.Y. Jing, L.Y. Xu, Y.D. Han, L. Zhao, The influence of microstructural evolution on selective corrosion in duplex stainless steel flux-cored arc welded joints, Corros. Sci. 120 (2017) 194-210.

[26] Z.Q. Zhang, H.Y. Jing, L.Y. Xu, Y.D. Han, L. Zhao, J.L. Zhang, Influence of microstructure and elemental partitioning on pitting corrosion resistance of duplex stainless steel welding joints, Appl. Surf. Sci. 394 (2017) 297-314.

[27] Z.Q. Zhang, H.Y. Jing, L.Y. Xu, Y.D. Han, L. Zhao, Investigation on microstructure evolution and properties of duplex stainless steel joint multi-pass welded by using different methods, Mater. Des. 109 (2016) 670-685.

[28] A. Eghlimi, M. Shamanian, M. Eskandarian, A. Zabolian, J.A. Szpunar, Characterization of microstructure and texture across dissimilar super duplex/austenitic stainless steel weldment joint by austenitic filler metal, Mater. Char. 106 (2015) 208-217.

[29] I.V. Aguiar, D.P. Escobar, D.B. Santos, P.J. Modenesi, Microstructure characterization of a duplex stainless steel weld by electron backscattering diffraction and orientation imaging microscopy techniques, Matéria (Rio de Janeiro) 20 (2015) 212-226.

[30] R. Badji, B. Bacroix, M. Bouabdallah, Texture, microstructure and anisotropic properties in annealed 2205 duplex stainless steel welds, Mater. Char. 62 (2011) 833-843.

[31] T.J. Headley, J.A. Brooks, A New Bcc-Fcc Orientation Relationship Observed between Ferrite and Austenite in Solidification Structures of Steels, Metall. Mater. Trans. A 33A (2002) 5-15.

[32] T. Tomida, Variant selection mechanism by elastic anisotropy and double K-S relation for transformation texture in steel; difference between martensite and ferrite, Aata Mater. 146 (2018) 25-41.

[33] J.J. Jonas, N.J. Wittridge, The $\gamma$-to- $\alpha$ transformation of hot rolled austenite, Met. Mater. 6 (2000) 211-220.

[34] O. Engler, V. Randle, Introduction to texture analysis : macrotexture, microtexture, and orientation mapping, CRC press, London, 2010.

[35] H.J. Bunge, Texture analysis in materials science: Mathematical Methods, Butterworths, 
London, 1982.

[36] M. Milititsky, N. De Wispelaere, R. Petrov, J.E. Ramos, A. Reguly, H. Hänninen, Characterization of the mechanical properties of low-nickel austenitic stainless steels, Mater. Sci. Eng. A 498 (2008) 289-295.

[37] W.M. Mao, X.M. Zhang, Quantitative texture analysis of crystalline materials, Metallurgical Industry Press, China, 1993.

[38] H.Y. Jing Z.Q Zhang, L.Y. Xu, Y.D. Han, Z.Q. Gao, L. Zhao, J.L. Zhang, Microstructural characterization and electron backscatter diffraction analysis across the welded interface of duplex stainless steel, Appl. Surf. Sci. 413 (2017) 327-343.

[39] X.Y. Zhang, Q. Zhou, K.H. Wang, Y. Peng, J.L. Ding, J. Kong, S. Williams, Study on microstructure and tensile properties of high nitrogen Cr-Mn steel processed by CMT wire and arc additive manufacturing, Mater. Des. 166 (2019).

[40] F. Liu, Z.Y. Liu, M. Liu, Y.C. Hu, Y. Chen, S. Bai, Texture Evolution and Its Effect on Fatigue Crack Propagation in Two 2000 Series Alloys, J. Mater. Eng. Perform. 28 (2019) 13241336.

[41] B. Dönges, A. Giertler, U. Krupp, C.P. Fritzen, H.J. Christ, Significance of crystallographic misorientation at phase boundaries for fatigue crack initiation in a duplex stainless steel during high and very high cycle fatigue loading, Mater. Sci. Eng. A 589 (2014) 146-152.

[42] Z.Q. Zhang, H.Y. Jing, L.Y. Xu, Y.D.Han, L. Zhao, J.L. Zhang, Influence of microstructure and elemental partitioning on pitting corrosion resistance of duplex stainless steel welding joints, Appl. Surf. Sci. 394 (2017) 297-314.

[43] A.J.W. Menezes, H. Abreu, S. Kundu, H.K.D.H. Bhadeshia, P.M. Kelly, Crystallography of Widmanstätten austenite in duplex stainless steel weld metal, Sci. Technol. Weld. Joi. 14 (2013) 4-10.

[44] L. Karlsson, J. Börjesson, Orientation relationships of intragranular austenite in duplex stainless steel weld metals, Sci. Technol. Weld. Joi. 19 (2014) 318-323.

[45] Z.Q. Zhang, H.Y. Jing, L.Y. Xu, Y.D. Han, L. Zhao, X.Q. Lv, J.Y. Zhang, The impact of annealing temperature on improving microstructure and toughness of electron beam welded duplex stainless steel, J. Manuf. Process. 31 (2018) 568-582.

[46] S. Patra, A. Ghosh, V. Kumar, D. Chakrabarti, L.K. Singhal, Deformation induced austenite formation in as-cast 2101 duplex stainless steel and its effect on hot-ductility, Mater.

Sci. Eng. A 660 (2016) 61-70.

[47] S.C. Li, C.Y. Guo, L.L. Hao, Y.L. Kang, Y.G. An, In-situ EBSD study of deformation behaviour of $600 \mathrm{MPa}$ grade dual phase steel during uniaxial tensile tests, Mater. Sci. Eng. A 759 (2019) 624-632.

[48] Y.H. Yang, B. Yan, J. Li, J. Wang, The effect of large heat input on the microstructure and corrosion behaviour of simulated heat affected zone in 2205 duplex stainless steel, Corros. Sci. 53 (2011) 3756-3763. 


\section{Element partitioning and electron}

backscatter diffraction analysis from

feeding wire to as-deposited

microstructure of wire and arc additive

manufacturing with super duplex

stainless steel

Zhang, Xiaoyong

Elsevier

Zhang X, Wang K, Zhou Q, et al., (2020) Element partitioning and electron backscatter diffraction analysis from feeding wire to as-deposited microstructure of wire and arc additive manufacturing with super duplex stainless steel. Materials Science and Engineering A:

Structural Materials: Properties, Microstructures and Processing, Volume 773, January 2019, Article number 138856

https://doi.org/10.1016/j.msea.2019.138856

Downloaded from Cranfield Library Services E-Repository 